\title{
Aggregate QT Interval
}

National Cancer Institute

\section{Source}

National Cancer Institute. Aggregate QT Interval. NCI Thesaurus. Code C117783.

An aggregate QT value based on the measurement of QT intervals from multiple beats

within a single ECG. The method of aggregation, which can vary, is typically a measure of central tendency such as the mean. (CDISC) 